\title{
EFEKTIVITAS PENERAPAN UJIAN TANPA PENGAWASAN MELALUI PENDIDIKAN KARAKTER BERBASIS HADIST DI SMA ISLAM ATHIRAH BOARDING SCHOOL BONE
}

\author{
Abdul Hakim \\ Institut Agama Islam Negeri Bone \\ Eail: hakim150828@gmail.com \\ Fajri Dwi Yama \\ Institut Agama Islam Negeri Bone \\ fajridwiyama@gmail.com
}

Naskah Diterima: 10-12-2019 Direvisi: 24-01-2019 Disetujui: 01-02-2020

Kata kunci: Ujian tanpa pengawasan, Pendidikan karakter, Hadits.

Abstract

This study aims to describe the effectiveness of the unsupervised exam program through the character education of students at the Athirah Bone Islamic High School. In this study using descriptive qualitative methods, the subject of the principal's research, curriculum, class teachers, school employees and Athirah Bone Islamic High School students. Data collection techniques using observation, interviews, questionnaires, and documentation. Checking the validity of the data uses triangulation and objectivity. The results showed the effectiveness of the unsupervised exam on character education based on the hadith of Islamic Athirah Bone bigh school students. Through exams without supervision students bave the character of Honesty, discipline, responsibility, independence, and personality.

Keywords: Unattended exams, Character Educatin, Hadith 


\section{PENDAHULUAN}

Pendidikan karakter akhir-akhir ini semakin banyak diperbincangkan di tengah-tengah masyarakat Indonesia, terutama oleh kalangan akademisi. Sikap dan perilaku masyarakat dan bangsa Indonesia yang sekarang ini cenderung mengabaikan nilai-nilai luhur yang sudah lama dijunjung tinggi dan mengakar dalam sikap dan perilaku sehari-hari. ${ }^{1}$ Nilai-nilai karakter mulia, seperti kejujuran, kesantunan, kebersamaan, dan religius, sedikit demi sedikit mulai terkikis oleh budaya asing yang cenderung hedonistik, materialistik, dan individualistik, sehingga nilainilai karakter tersebut tidak lagi dianggap penting jika bertentangan dengan tujuan yang ingin diperoleh. ${ }^{2}$

Pendidikan karakter hadir sebagi solusi problem moralitas dan karakter itu. Meski bukan sebagai sesuatu yang baru, pendidikan karakter cukup menjadi semacam "greget" bagi dunia pendidikan pada khususnya untuk membenahi moralitas generasi muda. ${ }^{3}$ Berbagai alternatif guna mengatasi krisis karakter, memang sudah dilakukan dan penerapan hukum yang lebih kuat. Altenatif lain yang banyak dikemukakan untuk mengatasi, paling tidak mengurangi masalah budaya dan karakter bangsa yang dibicarakan itu adalah melalui pendidikan karakter. ${ }^{4}$ Menurut Kemendiknas, pendidikan dianggap sebagai alternatif yang bersifat preventif $f^{5}$. Itu karena pendidikan membangun generasi baru bangsa menjadi lebih baik. Sebagai alternatif yang bersifat preventif, ${ }^{6}$ pendidikan diharapkan mengembangkan kualitas generasi muda bangsa ini dalam berbagai aspek, serta dapat memperkecil dan mengurangi penyebab berbagai masalah budaya dan karakterbangsa. ${ }^{7}$

1 Ansori, "Internalisasi Nilai-Nilai Pendidikan Karakter Dilingkungan Madrasah Dan Sekolah," At-Tasyrib: Jurnal Pendidikan Islam 1, no. 1 (1 September 2015): 66-81.

2 A. Dawam, A. Ta'arifin, dan K. Durori, Manajemen madrasab berbasis pesantren (Lista Fariska Putra, 2004), 2, https://books.google.co.id/books?id=UjYdNAAACAAJ.

${ }^{3}$ Hasan Baharun dan Rohmatul Ummah, "Strengthening Students' Character in Akhlaq Subject Through Problem Based Learning Model," Tadris: Jurnal Keguruan Dan Ilmu Tarbiyah 3, no. 1 (29 Juni 2018): 21-30, https://doi.org/10.24042/tadris.v3i1.2205; Danilo Garcia, Trevor Archer, dan Ann-Christine Andersson Arntén, Character, Responsibility, and Well-Being: Influences on Mental Health and Constructive Behavior Patterns, 2016.

4 Agus Wibowo, Pendidikan karakter: strategi membangun karakter bangsa berperadaban, Cet. 1 (Yogyakarta: Pustaka Pelajar, 2012), 25; Chairul Anwar dkk., "The Effectiveness of Islamic Religious Education in the Universities: The Effects on the Students' Characters in the Era of Industry 4.0," Tadris: Jurnal Keguruan Dan Ilmu Tarbiyah 3, no. 1 (29 Juni 2018): 77-87, https://doi.org/10.24042/tadris.v3i1.2162; Muhammad Anas Ma'arif dan Muhammad Husnur Rofiq, "The Model of Character Teacher: Phenomenology at Daruttaqwa Gresik Islamic Boarding School," ATTARBIYAH: Journal of Islamic Culture and Education 3, no. 2 (2 Januari 2019): 131-52, https://doi.org/10.18326/attarbiyah.v3i2.131-152.

5 Muhammad Anas Ma arif, "Analisis Strategi Pendidikan Karakter Melalui Hukuman Preventif," Ta'allum: Jurnal Pendidikan Islam 6, no. 1 (6 Maret 2018): 31-56, https://doi.org/10.21274/taalum.2018.6.1.31-56.

6 Abdallah Abdallah, "State, Religious Education, and Prevention of Violent Extremism in Southeast Asia," Studia Islamika 26, no. 2 (13 Agustus 2019): 407-15, https://doi.org/10.15408/sdi.v26i2.12204.

7 Kementerian Pendidikan Nasional, "Pengembangan Pendidikan Budaya dan Karakter Bangsa" (Badan Penelitian dan Pengembangan Pusat Kurikulum. Jakarta, 2011). 
Sementara itu, dalam dunia pendidikan kasus bertindak curang baik berupa tindakan mencontek, mencontoh pekerjaan teman atau mencontoh dari buku pelajaran seolah-olah merupakan kejadian sehari-hari. ${ }^{8}$ Bahkan dalam pelaksanaan ujian akhir sekolah di beberapa daerah ditengarai ada guru yang memberikan kunci jawaban kepada siswa, karena takut muridnya tidak lulus sehingga mencoreng nama sekolah. Seakan-akan dalam dunia pendidikan kejujuran telah menjadi barang yang langka, contoh hilangnya kepercayaan masyarakat Indonesia seperti maraknya korupsi dan kolusi sudah amat banyak.

Kekuasaan (power) dan kejujuran perlu ditanamkan tidak hanya pada siswa sekolah dan guru. Kejujuran perlu ditanamkan pada pembuat kebijakan (power) juga. Semoga lintas dimensi kehidupan bisa bersama-sama menjunjung kejujuran di mana saja dan kapan saja ${ }^{10}$. Masyarakat atau orang tua bisa sadar bahwa jika putera-puterinya tidak jujur, mereka akan membebani orang tua mereka sendiri kelak jika sudah menjadi orang dewasa. Jadi pendidikan dan kejujuran senantiasa ditegakkan di mana saja dengan singkronisasi materi ajar dan sikap. ${ }^{11}$

Kebijakan pemerintah ini, pada tataran realitanya ternyata menuai pro dan kontra. Di mana masing-masing pihak memiliki pernyataan-pernyataan yang argumentatif, dalam mempertahankan opininya. Tetapi, terlepas dari adanya pro dan kontra terhadap kebijakan tersebut, SMA Islam Athirah Boarding School Bone berusaha untuk menerapkan pendidikan karakter bagi siswanya. Salah satu bentuk penerapannya adalah melalui ujian tanpa pengawasan.

Berdasarkan latar belakang tersebut maka dalam tulisan ini, penulis ingin menetralisir masalah ini melalui tinjauan syariat Islam yang secara khusus merujuk kepada hadis-hadis Rasulullah. Di mana yang menjadi sorotan kajiannya adalah melihat efektivitas penerapan ujian tanpa pengawasan melalui pendidikan karakter berbasis hadis di SMA Islam Athirah Boarding School Bone.

${ }^{8}$ Muhammad Amri, Saharuddin Saharuddin, dan La Ode Ismail Ahmad, "The Implementation of Islamic Education: The Process of Instilling Akhlakul Karimah (Noble Characters) for Madrasah Tsanawiyah Students," Tadris: Jurnal Keguruan Dan Ilmu Tarbiyah 4, no. 1 (28 Juni 2019): 117-25, https://doi.org/10.24042/tadris.v4i1.4070.

9 Samani Muclas dan Hariyanto, Konsep dan Model Pendidikan karakter, 6 ed. (Bandung: Rosdakarya, 2017), 5.

${ }^{10}$ Ichsan Ichsan, "Pendidikan Nilai Kejujuran Berbasis Kelas Di Madrasah Ibtidaiyah Negeri 1 Bantul Yogyakarta," Edukasia: Jurnal Penelitian Pendidikan Islam 14, no. 1 (24 Juni 2019): 49-70, https://doi.org/10.21043/edukasia.v14i1.3664.

11 Asror Baisuki dan Ta'rif Ta’rif, "Penanaman Karakter Moderat Di Ma'had Aly Situbondo," EDUKASI: Jurnal Penelitian Pendidikan Agama Dan Keagamaan 15, no. 3 (31 Desember 2017), https://doi.org/10.32729/edukasi.v15i3.456; Abdul Malik Karim Amrullah, "Implementasi Pendidikan Karakter Di Madrasah," Madrasab: Jurnal Pendidikan Dan Pembelajaran Dasar 4, no. 2 (23 November 2012), https://doi.org/10.18860/jt.v0i0.2183. 


\section{THEORI PERUBAHAN SIKAP}

Menurut Eagly dan Chaiken yang dikutip oleh Neila Ramdani bahwa ada tiga teori perubahan sikap yaitu: 1) Probabilogical model yaitu perubahan sikap ditentukan oleh keyakinan yang sudah dimilikinya yang bersifak subyektif. 2) Expetancy value model yaitu perubahan sikap ditentukan oleh sekumpulan keyakinan tentang suatu obyek, perilaku dan peristiwa. Information integration teori yaitu teori yang mengatakan bahwa perubahan sikap terbentuk dan dimodifikasi oleh setiap individu pada saat menerima informasi baru. ${ }^{12}$

Sehubungan dengan hal ini Paul E Johnson Sebagaimana yang dikutip oleh Imam Suprayogo dan Tobroni mengatakan bahwa perilaku beragama seseorang dapat ditentukan oleh kesadaran syariat dan kesadaran spiritual mereka. Sehin gga dengan demikian agama dapat berfungsi untuk menjaga kesusilaan atau tata krama dan tata tertib yang berlaku dalam masyarakat. ${ }^{13}$ Berdasarkan dua teori tersebut di atas maka dapat dilihat bahwa adanya kepercayaan terhadap sumber ajaran agama dapat mempengaruhi perilaku seseorang. Oleh karena itu dalam penelitian ini akan dilihat apakah pembentukan karakter dapat dilakukan melalui dengan pengembangan pendidikan berbasis hadis.

\section{Pendidikan Karakter}

Megawangi mendefinisikan pendidikan karakter sebagai sebuah usaha untuk mendidik anak-anak agar dapat mengambil keputusan dengan bijak dan mempraktikkannya dalam kehidupan sehari-hari, sehingga mereka dapat memberikan kontribusi positif kepada lingkungannya. ${ }^{14}$ Bahwasanya karakter merupakan kepribadian yang telah mendarah daging di dalam diri seseorang sehingga setiap perbuatan yang dilakukannya adalah perbuatan yang dilakukan secara spontan dan tanpa memerlukan pertimbangan terlebih dahulu ${ }^{15}$.

Definisi lain dikemukakan oleh Fakry Gaffar "Sebuah proses tranformasi nilai-nilai kehidupan untuk ditumbuhkembangkan dalam kepribadian seseorang sehingga menjadi satu dalam perilaku kehidupan orang tersebut."16 Jadi karakter itu mengakar pada kepribadian yang merupakan pendorong perilaku bagaimana bertindak, bersikap, berujar dan merespon sesuatu.

12 Neila Ramdani, “Teori Perubahan Sikap” (Makalah Pendidikan Program Doktor Fakultas Psikologi UGM, Yogjakarta, 2008), 1-2. 64-65.

13 Suprayogo Imam dan Tobroni, Metodologi Penelitian Sosial Agama (Bandung: Remaja Rosdakarya, 2003),

${ }^{14}$ M. Jafar Anwar dan M. A. Salam, Membumikan Pendidikan Karakter Implementasi Pendidikan Berbobot Nilai dan Moral, (Jakarta: Suri Tatu 'uw, 2015), 32.

15 Zubaedi, Desain Pendidikan karakter, Konsepsi dan Aplikasinya dalam Pendidikan (Jakarta: Kencana Prenada, 2011); Thomas Lickona, Educating for Character: How Our Schools Can Teach Respect and Responsibility (New York: Bantam Books, 2009).

16 Dharma Kesuma, Pendidikan karakter: kajian teori dan praktik di sekolah (Bandung: PT Remaja Rosdakarya, 2011), 5. 
Buchori mengemukakan bahwa pendidikan karakter seharusnya membawa peserta didik ke pengenalan nilai secara kognitif, penghayatan nilai secara afektif, dan pengamalan nilai secara nyata. ${ }^{17}$ Dengan kata lain adanya pendidikan karakter peserta didik harus mampu mengetahui dan mengamati nilai-nilai karakter yang baik ataupun buruk sehingga mampu menyikapinya berdasarkan pengalamannya.

Berdasarkan beberapa pendapat dapat disimpulkan bahwa pendidikan karakter merupakan proses pemberian tuntutan yang positif kepada peserta didik agar menjadi manusia yang berkarakter dalam mengolah hati, pikiran, raga, serta rasa. Pendidikan karakter dapat dimaknai sebagai pendidikan nilai, pendidikan budi pekerti, pendidikan watak yang mengembangkan kemampuan peserta didik dalam memelihara yang baik, dan mewujudkan kebaikan itu dalam pengamalan kehidupan sehari-hari dengan sepenuh hati.

\section{Tujuan Pendidikan Karakter}

Pendidikan karakter dalam perspektif Islam telah ada sejak diutusnya Nabi Muhammad Saw, Sang Nabi terakhir dalam ajaran Islam mempertegas bahwa misi utamanya dalam mendidik manusia adalah untuk memperbaiki atau menyempurnakan pembentukan karakter yang baik (good character). ${ }^{18}$ Jadi pendidikan karakter bertujuan untuk mengembangkan kemampuan perserta didik agar mereka mengetahui kebaikan, mencintai kebaikan dan dapat mengamalkan kebaikan dalam kehidupannya sehari hari secara reflek dan dengan sepenuh hati sehingga nantinya setiap manusia dapat hidup berdampingan dengan kedamaian.

Mulyasa mengatakan bahwa tujuan dari pendidikan karakter yaitu, untuk meningkatkan mutu proses dan hasil pendidikan yang mengarah pada pembentukan karakter dan akhlak mulia peserta didik secara utuh, terpadu, dan seimbang, sesuai dengan standar kompetensi lulusan pada setiap satuan pendidikan. ${ }^{19}$ Melalui pendidikan karakter siswa dapat mengembangkan sikap mandiri untuk meningkatkan dan menggunakan pengetahuan yang dimiliki, mempelajari dan memahami nilai-nilai karakter dan akhlak mulia sehingga dapat terwujud dalam perilaku sehari- hari.

Dengan demikian tujuan adanya pendidikan karakter yaitu sebagai bentuk pengembangan nilai-nilai perilaku positif yang diwujudkan dalam proses pembelajaran di sekolah yang berdampak di luar sekolah.

\footnotetext{
${ }^{17}$ E Mulyasa, Manajemen Pendidikan Karakter, 5 ed. (Jakarta: Bumi Aksara, 2016), 8-9.

18 Abdul Majid dan Dian Andayani, Pendidikan agama Islam berbasis kompetensi: konsep dan implementasi kurikulum 2004, Cet. 1 (Bandung: Remaja Rosdakarya, 2004), 30.

${ }^{19}$ E Mulyasa, Manajemen, 9.
} 


\section{Pendidikan Karakter Dalam Perspektif Hadits.}

Ahmad Tafsir dalam dua bukunya Filsafat Pendidikan Islami dan Ilmu Pendidikan Islami mencantumkan bab tentang pengembangan pendidikan di bagian akhir dalam buku tersebut. Ini menunjukkan spektrum yang harus ditempuh para praktisi pendidikan untuk menggapai kesuksesan dalam proses pendidikan. Dengan landasan filosofisnya adalah keyakinan bahwa semua pengetahuan datang dari Allah Ta ala. Tentu pendapat ini adalah sangat dibenarkan, mengingat betapa banyak ayat-ayat al-Qur'an dan hadits Rasulullah saw. yang menegaskan perkara ini. ${ }^{20}$

\section{Nilai-Nilai Karakter Berbasis Hadits}

Adapun ayat-ayat dan hadits yang berhubungan dengan Akhlak terpuji (mahmud-ah) banyak sekali, seperti hadits tentang kejujuran, kemandirian, kepribadian, tanggung jawab, kedisiplinan dan sebagainya. Dari kelima karakter inilah yang menjadi fokus penelitian ini menurut penulis perlu dikembangkan dan ternyata sejalan sesuai yang tercantum pada Pusat Kurikulum Kemendiknas Tahun 2011, yaitu beberapa karakter sebagai berikut:

\section{Kejujuran}

Jujur merupakan akhlak terpuji dan termasuk sifat dan kepribadian dari Nabi Muhammad. SAW. yang dikenal dengan sifat shiddiq dan amanah, yaitu benar dan dapat dipercaya, sehingga beliau digelari al-amin (seorang laki-laki yang jujur, dan ibunya bernama aminah, seorang perempuan yang jujur). ${ }^{21} \mathrm{Di}$ antara hadits tentang kejujuran adalah ${ }^{22}$ :

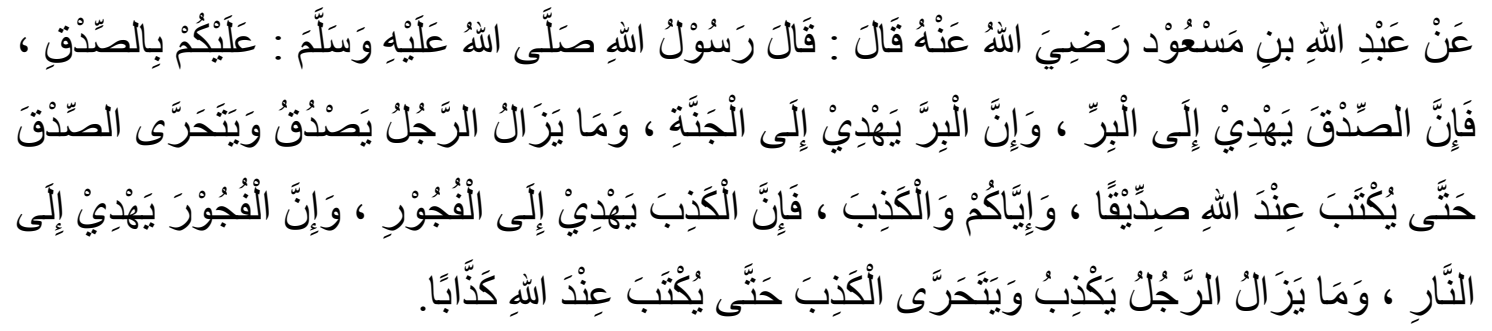

"Artinya: Dari 'Abdullâh bin Mas'ûd Radhiyallahu anbu, ia berkata: "Rasûlullâh Shallallahu 'alaibi wa sallam bersabda, Hendaklah kalian selalu berlaku jujur, karena kejujuran membawa kepada kebaikan, dan kebaikan mengantarkan seseorang ke Surga. Dan apabila seorang selalu berlaku jujur dan tetap memilih jujur, maka akan dicatat di sisi Allâh sebagai orang yang jujur.

${ }^{20}$ Ramayulis dan Samsul Nizar, Filsafat pendidikan Islam: telaah sistem pendidikan dan pemikiran para tokohnya (Jakarta: Kalam Mulia, 2009); Nata Abudin, Ilmu Pendidikan Islam, 3 ed. (Jakarta: Prenada Media Grup, 2016); Zakiah Daradjat dan Indonesia, ed., Ilmu pendidikan Islam, Cet. 2 (Jakarta: Diterbitkan atas kerjasama Penerbit Bumi Aksara, Jakarta dengan Direktorat Jenderal Pembinaan Kelembagaan Agama Islam, Departemen Agama, 1992).

21 Marsidin Sufyarma, "Pendidikan Karakter di Pesantren" (Makalah Seminar RegionaTentang Pendidikan Karakter STIT Ahlussunnah Bukittinggi, Bukittinggi, 2012).

${ }^{22}$ Isa al-Tirmidhy Abu 'Isa Muhammad, Sunan al-Tirmidhy (Riyad: Maktabat al-Ma'arif, 2005), 658. 
Dan jaubilah oleh kalian berbuat dusta, karena dusta membawa seseorang kepada kejahatan, dan kejahatan mengantarkan seseorang ke Neraka. Dan jika seseorang senantiasa berdusta dan memilih kedustaan maka akan dicatat di sisi Allâh sebagai pendusta (pembohong)."

\section{Kemandirian}

Manusia dituntut hidup mandiri dan tidak tergantung kepada orang lain, baik sebagai individu ataupun sebagai masyarakat. Di antara ayat yg berkaitan dengan masalah ini adalah: beliau Rasulullah saw bersabda:

$$
\text { مروا أبناءكم بالصلاة لسبع ، و اضربو هم عليها لعثر ، وفرقو ا بينهم في المضاجع } 23
$$

"Artinya: "Perintabkan anak kalian untuk shalat saat mereka berusia tujub tabun, pukullah mereka (jika tidak melaksanakan shalat) saat mereka berusia sepulub tabun. Bedakan mereka di tempat tidurnya."

Hadits ini menyatakan bahwa beban yang dipikulkan kepada manusia hanya sebatas kemampuannya, manusia sebagai individu akan menerima reward (penghargaan/pahala) atau menerima punishmen (ancaman) atas perbuatannya sendiri.

\section{Kepribadian}

Konsep diri merupakan penentu sikap individu dalam bertingkah laku, artinya apabila individu cenderung berpikir akan berhasil, maka hal ini merupakan kekuatan atau dorongan yang akan membuat individu menuju kesuksesan. ${ }^{24}$

Dapat dilihat dalam haditsnya sebagai berikut: 1). Hadits tentang Kepribadian tentang keutamaan berbuat kebajikan:

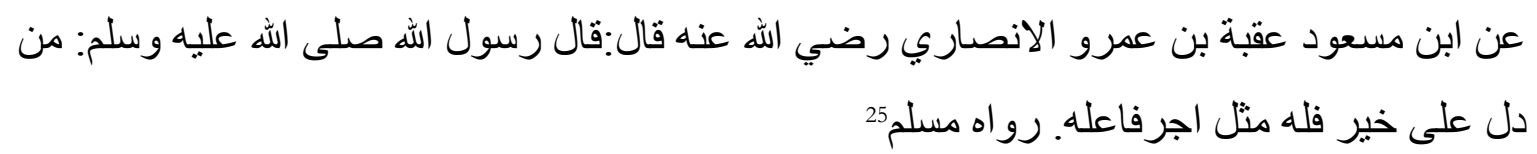

"Artinya: Ibnu Mas'ud (Uqbah bin Amr) al-Anshari al-Badari r.a meriwayatkan bahwasanya Rasulullah saw bersabda:"Barang siapa yang memberi petunjuk pada (jalan) kebaikan, baginya pahala sebesar pahala orang yang melakukannya."

\section{Tanggung Jawab}

Setiap orang harus bertanggung jawab atas perbuatan yang dilakukannya, semua tindakan akan dipertanggung- jawabkan baik di dunia atau di akhirat kelak, baik tanggung

23 Yazid al-Qazwiny Ibn Majah Abu 'Abd Allah Muhammad, Sunan Ibn Majah (Riyad: Maktabah alMa'arif, t.t.), 56.

${ }^{24}$ Yaya Suryana, Pendidikan multikulkultural: suatu upaya penguatan jati diri bangsa: konsep-prinsip-implementasi, Cet. I (Bandung: Pustaka Setia, 2015).

25 Al-Sijistany al-Azdy Sulaiman bin al-Ash'ath, Sunan Abu Dawnd, vol. 4 (Beirut Lebanon: Dar Ibn Hazm, 1997), 40 . 
jawab terhadap Allah dan Rasul maupun terhadap orang lain sesama manusia, bahkan terhadap diri sendiri, di antara hadits yang berhubungan dengan ini adalah: ${ }^{26}$

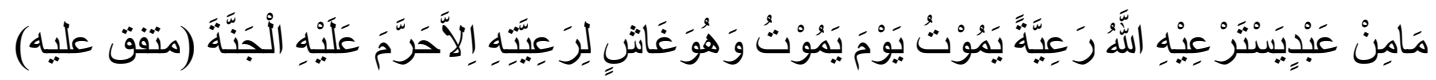

Artinya: "Tiada lain bagi seorang hamba yang diamanatkan oleh Allah SWT mengurusi rakyat yang pada suatu hari ia mati dalam keadaan menipu rakyatnya atau tidak bertanggung jawab, kecuali Allah mengharamkan surga untuknya." (HR. Muttafaq 'alaib).

Penjelasan hadits di atas adalah Orang yang memiliki sifat bertanggung jawab di hadapan Allah SW'T segala perbuatannya akan selalu dipertimbangkan, agar bermanfaat dan tidak mendatangkan kerusakan atau kemaksiatan. ${ }^{27}$

\section{Kedisiplinan}

Berlaku disiplin sangat diperlukan, di antara hadits Rasulullah saw yang ber hubungan dengan disiplin adalah $:^{28}$

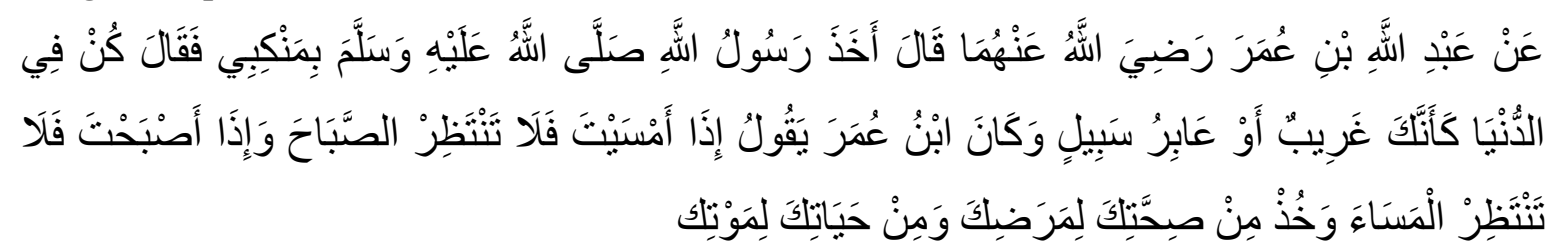

Dari Ibnu Umar Radbiallabu Anbuma, ia berkata: "Rasulullah Shallallabu Alaibi Wasallam memegang pundakeku, lalu bersabda: Jadilah engkau di dunia ini seakan-akan sebagai orang asing atau pengembara. Lalu Ibnu Umar Radbiallahu Anbuma berkata: "Tika engkan di waktu sore, maka janganlah engkau menunggu pagi dan jika engkau di waktu pagi, maka janganlah menunggu sore dan pergunakanlah waktu sehatmu sebelum kamu sakit dan waktu bidupmu sebelum kamu mati”. (HR. Bukhari, Kitab Ar Riqaq).

Hadits di atas mengajarkan kepada kita bahwa dalam hidup ini kita harus menjadi manusia-manusia yang disiplin.

\section{Deskripsi Ujian tanpa Pengawasan.}

Pengertian Ujian

Ujian sekolah adalah kegiatan pengukuran pencapaian kompetensi peserta didik yang dilakukan oleh satuan pendidikan untuk memperoleh pengakuan atas prestasi belajar dan merupakan salah satu persyaratan kelulusan dari satuan pendidikan. Mata pelajaran yang diujikan adalah mata pelajaran kelompok mata pelajaran ilmu pengetahuan dan teknologi yang

${ }^{26}$ Muhammad bin Ismail Abu Abdullah, Shahih Bukhari, 4 ed. (Beirut Lebanon: Dar al-Kotob Al-Ilmiyah, 2010), Vol 140

27 Prayitno Irwan, Pendidikan Karakter, 2012 ed. (Singgalang, t.t.), 1. 2074.

28 Al-Hajjaj Abu Husain Muslim, Shahih Muslim, 3 ed. (Beirut Lebanon: Dar al-Kotob Al-Ilmiyah, 2010), 
Efektivitas Penerapan Ujian,..

tidak diujikan dalam ujian nasional dan aspek kognitif dan/atau psikomotorik kelompok mata pelajaran agama dan akhlak mulia serta kelompok mata pelajaran kewarganegaraan dan kepribadian yang akan diatur dalam POS Ujian Sekolah/Madrasah (Peraturan Menteri Pendidikan Nasional Nomor 20 Tahun 2007 tentang Standar Penilaian Pendidikan Lampiran A 8 )

Sukardi mengatakan "Hubungan antara evaluasi, pengukuran, ujian dan tes adalah sangat erat, saling mendukung dalam usaha seorang pendidik memperoleh informasi yang komprehensif terhadap peserta didik. Evaluasi pendidikan merupakan proses di mana seorang guru menggunakan informasi yang diturunkan dari beberapa sumber informasi agar dapat mencapai tingkat pengambilan keputusan dengan benar. ${ }^{29}$ Dalam hal ini, evaluasi bias dilakukan, baik melalui pengukuran maupun tanpa pengukuran, di mana siswa memiliki sifat yang diidentifikasi dan dimodifikasi sebagai hasil pengalaman pendidikan. Keberadaan alat pengukuran yang baik, dapat membantu guru dalam pengambilan keputusan. Evaluasi merupakan proses inklusif dari pengukuran, sedangkan pengukuran hanyalah bagian dari evaluasi."

Waktu pelaksanaan ujian sekolah adalah pada akhir tahun akademik sesuai kalender pendidikan satuan pendidikan. Ujian sekolah dilaksanakan oleh satuan pendidikan dengan membentuk panitia ujian sekolah yang ditetapkan pada awal tahun akademik. Cakupan ujian sekolah adalah seluruh indikator yang mempresentasikan seluruh standar kompetensi lulusan yang ditetapkan oleh Kementrian Pendidikan Nasional. Hasil analisis ujian sekolah dipergunakan pendidik dan satuan pendidikan untuk perbaikan proses pembelajaran secara keseluruhan pada tahun pelajaran berikutnya. Hasil ujian sekolah dilaporkan satuan pendidikan kepada orangtua peserta didik dalam bentuk surat keterangan hasil ujian (SKHU). Hasil ujian sekolah digunakan sebagai salah satu kriteria kelulusan yang telah dirumuskan oleh satuan pendidikan.

Persyaratan untuk mengikuti ujian sekolah adalah memenuhi persentasi minimal kehadiran peserta didik, mempunyai nilai hasil belajar lengkap dari semester 1 sampai dengan semester terakhir, terdaftar sebagai peserta ujian sekolah; dan memiliki ijazah atau surat keterangan lain yang setara dengan ijazah satuan pendidikan yang lebih rendah. Peserta didik yang tidak mengikuti ujian sekolah karena alasan tertentu, dapat mengikuti ujian sekolah susulan yang penjadwalannya diatur oleh satuan pendidikan.

Penerapan Ujian tanpa Pengawasan

\footnotetext{
${ }^{29}$ Sulistyorini, Evaluasi Pendidikan dalam Meningkatkan Mutu Pendidikan (Yogjakarta: Teras, 2009), 58-59.
} 
Ujian tanpa pengawasan telah diterapkan di SMA Islam Athirah Boarding School Bone sejak tahun 2015 yang lalu. System pengawasan ini diberlakukan dengan beberapa alasan, sebagai berikut : a) Melatih peserta didik agar memiliki prinsip jujur dalam hidupnya. b) Mengikuti ujian tanpa pengawasan juga akan melatih peserta didik dalam membentuk kepribadian serta kerja kerasnya. c) Menanamkan rasa segan dalam diri peserta didik akan tindakan negatif seperti curang, bohong dan semacamnya. ${ }^{30}$

\section{METODE PENELITIAN}

Penelitian ini tergolong penelitian lapangan atau field research, yaitu penulis melakukan penelitian langsung ke lokasi untuk mendapatkan dan mengumpulkan data. Jenis penelitian ini adalah penelitian deskriptif. Penelitian deskriptif menggambarkan prilaku, pemikiran atau perasaan suatu kelompok atau individu. Penelitian deskriptif merupakan penelitian yang bertujuan untuk memberikan uraian atau gambaran mengenai fenomena atau gejala sosial yang diteliti dengan mendeskripsikan varibel-variabel yang ada berdasarkan indikator dari variabel yang akan diteliti. Uleh karena itu penelitian ini akan mendeskripsikan ujian tanpa pengawasan melalui pendidikan karakter berbasis hadis di SMA Islam Athirah Boarding School Bone.

Penelitian ini berlokasi di SMA Islam Athirah Boarding School Bone merupakan salah-satu sekolah swasta yang ada di Kabupaten Bone yang cukup di akui oleh semua sekolah tidak hanya di lingkup Kabupaten Bone tetapi juga di Wilayah Sulawesi Selatan bahkan di skala nasional. Ini dikarenakan karena prestasi-prestasi yang membanggakan yang telah banyak diraih oleh siswa-siswinya, baik prestasi akademik maupun non akademik baik di tingkat lokal, regional maupun nasional. Termasuk penerapan berbagai metode pembelajaran yang digunakan oleh tenaga pendidiknya dalam pengembangan pendidikan karakter siswa.

Populasi adalah keseluruhan obyek peneltian yang dapat terdiri dari manusia, hewan, benda, tumbuh-tumbuhan atau sumber data lain yang memiliki karasteristik tertentu. ${ }^{31}$ Dalam sebuah penelitian yang akan dilaksanakan, faktor utama yang harus diperhatikan adalah populasi yang menyangkut jumlah keseluruhan obyek yang akan diteliti.

Populasi dari Penelitian ini adalah seluruh siswa SMA Islam Athirah Boarding School Kabupaten Bone yang berjumlah 187 orang ditambah dengan 1 Kepala Sekolah 4 Wakil Kepala Sekolah dan 8 0rang Wali Kelas. Sehingga jumlah populasi secara keseluruhan berjumlah 200 0rang dengan rincian sebagai berikut : 2018.

30 Sapriadi, Wawancara, Guru Bahasa Inngris SMA Islam Athirah Boarding School Bone, September

${ }^{31}$ Hadari Nawawi, Metode penelitian bidang sosial (Yogyakarta: Gadjah Mada University Press, 1993), 14. 


\begin{tabular}{llc}
\hline No & \multicolumn{1}{c}{ Kelas } & Jumlah Siswa \\
\hline $\mathbf{1}$ & X IPA Al-Fattah & 29 \\
$\mathbf{2}$ & X IPS Al-Alim & 24 \\
$\mathbf{3}$ & X IPS Al-Ghani & 24 \\
$\mathbf{4}$ & XI IPA Al-Hasiib & 26 \\
$\mathbf{5}$ & XI IPS Al-Hafiz & 20 \\
$\mathbf{6}$ & XI IPS Al-Haliim & 21 \\
$\mathbf{7}$ & XII IPA Al-Wajiid & 20 \\
$\mathbf{8}$ & XII IPS Al-Haadi & 23 \\
Jumlah & & 187 \\
\hline
\end{tabular}

Sampel dalam penelitian adalah $20 \%$ dari jumlah siswa sebanyak 38 orang ditambah dengan 1 Kepala Sekolah 4 Wakasek dan 8 Wali Kelas. Sehingga jumlah Sampel sebanyak 51 Orang. Namun karena yang akan disampel adalah jumlah siswa, karena inilah yang akan diberikan angket. Sementara Kepala Sekolah, Wakasek dan Guru-guru hanya diwawancarai sebagai data pendukung. Oleh karena itu cara pengambilan sampelnya adalah $20 \%$ dari tiap kelas dengan rincian sebagai berikut:

\begin{tabular}{clccc}
\hline No. & \multicolumn{1}{c}{ Kelas } & Populasi & Sampel \\
\hline $\mathbf{1}$ & X IPA Al-Fattah & 29 & 6 & \\
$\mathbf{2}$ & X IPS Al-Alim & 24 & 5 & \\
$\mathbf{3}$ & X IPS Al-Ghani & 24 & 5 \\
$\mathbf{4}$ & XI IPA Al-Hasiib & 26 & 5 \\
$\mathbf{5}$ & XI IPS Al-Hafiz & 20 & 4 \\
$\mathbf{6}$ & XI IPS Al-Haliim & 21 & 4 \\
$\mathbf{7}$ & XII IPA Al-Wajiid & 20 & 4 \\
$\mathbf{8}$ & XII IPS Al-Haadi & 23 & 5 \\
& & & \multicolumn{2}{|c}{38} \\
\hline
\end{tabular}

\section{Instrumen Penelitian}

Kisi-kisi pertanyaan yang menjadi pedoman dalam penelitian ini adalah sebagai berikut:

\begin{tabular}{lll}
\hline No & Aspek & \multicolumn{1}{c}{ Indikator } \\
\hline & & 1. Jujur \\
& & 2. Mandiri \\
1 & Ujian Tanpa Pengawasan & 3. Kerja Keras \\
& & 4. Bertanggung Jawab \\
& & 5. Disiplin \\
& & 1. Kejujuran \\
2 & Hadis Pendidikan Karakter & 2. Kemandirian \\
& & 3. Kepribadian \\
\hline
\end{tabular}


4. Tanggung Jawab

5. Kedisiplinan

Penelitian ini menggunakan analisis deskriptif kuantitatif yaitu menganalisis dan menginterpretasi data yang diperoleh dari lapangan dengan tekhnik statistik sederhana dengan rumus :

$$
\begin{aligned}
& \mathrm{P}=\frac{\mathrm{F}}{\mathrm{N}} \times 100 \% \\
& \text { Dimana } \\
& \mathrm{F}=\text { Frekwensi yang sedang dicari presentasenya } \\
& \mathrm{N}=\text { Jumlah Frekwensi/banyaknya individu } \\
& \mathrm{F}=\text { Angka presentase. }
\end{aligned}
$$

\section{HASIL PENELITIAN}

\section{Penerapan Ujian Tanpa Pengawasan di SMA Islam Athirah Boarding School Bone.}

Berdasarkan data yang penulis dapatkan di lapangan maka penerapan ujian tanpa pengawasan di SMA Islam Athirah Boarding School Bone dapat diklasifikasikan menjadi tiga bagian sebagai berikut :

\section{Latar Belakang Penerapan ujian Tanpa Pengawasan}

Ujian tanpa pengawasan telah diterapkan di SMA Islam Athirah Boarding School Bone sejak tahun 2015 yang lalu. Adapun yang menjadi alasan atau yang melatar belakangi sehingga ujian tanpa pengawasan ini dilaksanakan sebagaimana yang dikemukakan oleh Syamsul Bahri S.Pd.I adalah :

"Ujian tanpa pengawasan ini dilaksanakan karena hal ini sejalan dengan target atau tujuan yang ingin dicapai di sekolah ini yaitu agar out put yang dihasilkan diharapkan dapat menjadi pemimpin islami yang handal. Salah satu cara untuk menghasilkan yang seperti itu adalah tentu mereka harus memiliki sifat kepribadian yang baik, jujur, mandiri, disiplin dan bertanggungjawab. Untuk melatih sifat-sifat tersebut salah satu caranya adalah melalui ujian tanpa pengawasan." 32

Sejalan dengan hal ini, A. Eva Rukmana Thandra, S.Pd. mengatakan bahwa sistem ujian tanpa pengawasan ini diberlakukan dengan beberapa alasan, sebagai berikut :

a. Melatih peserta didik agar memiliki prinsip jujur dalam hidupnya.

32 Syamsul Bahri, Wawancara, Kepala Sekolah SMA Islam Athirah Boarding School Bone, Agustus 2019. 
b. Mengikuti ujian tanpa pengawasan juga akan melatih peserta didik dalam membentuk kepribadian serta kerja kerasnya.

c. Menanamkan rasa segan dalam diri peserta didik akan tindakan negatif seperti curang, bohong dan semacamnya. ${ }^{33}$

\section{Sosialisasi Prosedur Ujian Tanpa Pengawasan}

Sebelum ujian tanpa pengawsan ini dilaksanakan tentu didahului dengan sosialisasi terhadap peserta didik. Sebagaimana yang dikemukakan oleh Syamsul Bahri, S.Pd.I sebagai berikut:

"Di sekolah ini apa yang kita lakukan selalu secara kolektif. Termasuk dalam hal sosialisasi pelaksanaan ujian tanpa pengawasan selalu dilakukan oleh semua unsur yang ada di sekolah ini mulai dari Kepala sekolah, Wakil Kepala Sekolah, Wali Kelas, Guru-Guru, pegawai dan bahkan kakak-kakak kelas diperintahkan untuk mensosialisasikan kepada adik-adik mereka. Jadi sosialisasi tidak hanya dilkukan di kelas akan tetapi di mana saja termasuk ketika mereka ada di asrama pada malam hari." ${ }^{34}$

Sosialisasi pelaksanaan ujian tanpa pengawasan dalam rangka pembentukan karakter dilakukan sampai pada pelaksanaan ujian. Pengawas setelah memberikan soal, lembar jawaban dalam keadaan terbalik. Kemudian pengawas menyerahkan lembar jawaban untuk diletakkan di susdut meja kanan bersama dengan fakta integritas. Setelah itu sebelum peserta didik diperintahkan untuk menjawab soal, terlebih dahulu pengawas memberikan arahan tentang ujian tanpa pengawasan ini sebelum pengawas/penanggung jawab ruangan meninggalkan ruangan. ${ }^{35}$

\section{Efektivitas Penerapan Ujian Tanpa Pengawasan Terhadap Pengembangan} Pendidikan Karakter Siswa Berbasis Hadis di SMA Islam Athirah Boarding School Bone.

Berdasarkan hasil observasi yang peneliti lakukan selama terjun ke lapangan, maka hasil analisis peneliti tentang efektivitas penerapan ujian tanpa pengawasan terhadap pengembangan pendidikan karakter siswa berbasis hadis di SMA Islam Athirah Boarding School Bone sebagai berikut:

\section{Karakter Kejujuran}

Pandangan peserta didik tentang pentingnya sikap kejujuran dalam Penerapan Ujian

33 Eva Rukmana Thandra, Wawancara, Wakil Kepala Sekolah Bidang Kesiswaan SMA Islam Athirah Boarding School Bone, Agustus 2019. 2019.

${ }^{34}$ Syamsul Bahri, Wawancara, Kepala Sekolah SMA Islam Athirah Boarding School Bone, September

35 Rapika Samsu, Wwancara, Wali Kelas XI IPA Al-Hasiib, SMA Islam Athirah Boarding School Bone, Agustus 2019. 
Tanpa pengawasan melalui Pendidikan Karakter berbasis Hadis di SMA Islam Athirah Bone didapatkan hasil sebagai berikut:

Tabel 1.2

Hasil Jawaban Pernyataan Item 1

Pernyataan: "Apakah anda sepakat bahwa mencontek adalah sikap membohongi diri sendiri?"

\begin{tabular}{clcc}
\hline $\begin{array}{l}\text { No } \\
\text { Item }\end{array}$ & Alternatif Jawaban & Frekuensi & Presentase (\%) \\
\hline \multirow{2}{*}{$\mathbf{1}$} & Sangat Setuju (SS) & 34 & $\mathbf{8 9}$ \\
& Setuju (S) & 4 & $\mathbf{1 1}$ \\
& Tidak Setuju (TS) & 0 & $\mathbf{0}$ \\
& Sangat Tidak Setuju(STS) & 0 & $\mathbf{0}$ \\
\cline { 2 - 4 } & Jumlah & $\mathbf{3 8}$ & $\mathbf{1 0 0}$ \\
\hline
\end{tabular}

Pada tabel 1.2 Terlihat bahwa sebanyak 89\% siswa setuju bahwa mencontek adalah sikap membohongi diri sendiri. Hal tersebut menunjukkan budaya sekolah dalam ujian tanpa pengawasan telah efektif dalam membiasakan siswa untuk tidak mencontek.

\section{Karakter Kemandirian}

dari hasil pengumpulan data untuk penilaian karakter kemandirian melalui ujian tanpa pengawasan di SMA Islam Athirah Bone :

Tabel 1.3

Hasil Jawaban Pernyataan Item 17

Pernyataan: "Saya selalu menerima dengan lapang dada ketika pekerjaan ujian tidak maksimal"

\begin{tabular}{clcc}
\hline $\begin{array}{l}\text { No } \\
\text { Item }\end{array}$ & Alternatif Jawaban & Frekuensi & Presentase (\%) \\
\hline \multirow{2}{*}{} & Sangat Setuju (SS) & 22 & $\mathbf{5 7}$ \\
& Setuju (S) & 10 & $\mathbf{2 5}$ \\
\multirow{3}{*}{} & Kadang-Kadang & 6 & $\mathbf{1 8}$ \\
& Sangat Tidak Setuju(STS) & 0 & $\mathbf{0}$ \\
\cline { 2 - 4 } & Jumlah & $\mathbf{3 8}$ & $\mathbf{1 0 0}$ \\
\hline
\end{tabular}


Efektivitas Penerapan Ujian,..

Pada tabel 1.3 Terlihat bahwa sebanyak 57\% siswa sangat setuju dan $25 \%$ siswa setuju bahwa selalu menerima dengan lapang dada ketika pekerjaan ujian tidak maksimal. Hal tersebut menunjukkan budaya sekolah dalam ujian tanpa pengawasan telah efektif dalam membiasakan siswa untuk mandiri.

\section{Karakter Kepribadian}

Sehubungan dengan sikap kepribadian ini berikut hasil pengumpulan data untuk penilaian karakter kepribadian melalui ujian tanpa pengawasan di SMA Islam Athirah Bone :

Tabel 1.3

Hasil Jawaban Pernyataan Item 15

Pernyataan:

"Di asrama saya selalu mengulang-ulangi pelajaran yang telah diberikan"

\begin{tabular}{clcc}
\hline $\begin{array}{l}\text { No } \\
\text { Item }\end{array}$ & Alternatif Jawaban & Frekuensi & Presentase (\%) \\
\hline \multirow{2}{*}{} & Sangat Setuju (SS) & 34 & $\mathbf{8 9}$ \\
& Setuju (S) & 4 & $\mathbf{1 1}$ \\
$\mathbf{5}$ & Tidak Setuju (TS) & 0 & $\mathbf{0}$ \\
& Sangat Tidak Setuju(STS) & 0 & $\mathbf{0}$ \\
\cline { 2 - 3 } & Jumlah & $\mathbf{3 8}$ & $\mathbf{1 0 0}$ \\
\hline
\end{tabular}

Pada tabel 1.5 Terlihat bahwa sebanyak 89\% siswa sangat setuju dan 11 bahwa di asrama selalu mengulang-ulangi pelajaran yang telah diberikan. Hal tersebut menunjukkan budaya sekolah dalam ujian tanpa pengawasan telah efektif dalam membiasakan siswa untuk membentuk kepribadiannya.

\section{Karakter Tanggung Jawab}

Berikut hasil pengumpulan data untuk penilaian karakter tanggung jawab melalui ujian tanpa pengawasan di SMA Islam Athirah Bone :

\section{Tabel 1.5}

\section{Hasil Jawaban Pernyataan Item 20}

Pernyataan: "Saya mengumpulkan lembar jawaban tepat waktu meskipun tanpa pengawasan dari guru"

\begin{tabular}{llcc}
\hline $\begin{array}{l}\text { No } \\
\text { Item }\end{array}$ & Alternatif Jawaban & Frekuensi & Presentase (\%) \\
\hline & Sangat Setuju (SS) & 30 & $\mathbf{7 9}$ \\
& Setuju (S) & 8 & $\mathbf{2 1}$ \\
& & & \\
\hline
\end{tabular}




\begin{tabular}{lllc}
\hline $\mathbf{7}$ & Tidak Setuju (TS) & 0 & $\mathbf{0}$ \\
& Sangat Tidak Setuju(STS) & 0 & $\mathbf{0}$ \\
\cline { 2 - 4 } & Jumlah & $\mathbf{3 8}$ & $\mathbf{1 0 0}$ \\
\hline
\end{tabular}

Pada tabel 1.5 Terlihat bahwa sebanyak 79\% siswa sangat setujudan $21 \%$ setuju bahwa mengerjakan soal ujian dengan sebaik-baiknya meskipun tanpa pengawasan dari guru. Hal tersebut menunjukkan budaya sekolah dalam ujian tanpa pengawasan telah efektif dalam membiasakan siswa untuk bertanggung jawab.

\section{Kedisiplinan}

Tabel 1.6

Hasil Jawaban Pernyataan Item 4

Pernyataan: "Saya selalu hadir tepat waktu dalam ujian"

\begin{tabular}{clcc}
\hline $\begin{array}{l}\text { No } \\
\text { Item }\end{array}$ & Alternatif Jawaban & Frekuensi & Presentase (\%) \\
\hline \multirow{2}{*}{$\mathbf{9}$} & Sangat Setuju (SS) & 24 & $\mathbf{6 4}$ \\
& Setuju (S) & 11 & $\mathbf{2 9}$ \\
& Tidak Setuju (TS) & 3 & $\mathbf{7}$ \\
& Sangat Tidak Setuju(STS) & 0 & $\mathbf{0}$ \\
\cline { 2 - 4 } & Jumlah & $\mathbf{3 8}$ & $\mathbf{1 0 0}$ \\
\hline
\end{tabular}

Pada tabel 1.6 Terlihat bahwa sebanyak 64\% siswa sangat setuju dan $29 \%$ setuju bahwa "selalu hadir tepat waktu dalam ujian". Hal tersebut menunjukkan budaya sekolah dalam ujian tanpa pengawasan telah efektif dalam membiasakan siswa untuk disiplin.

\section{Analisa Data}

SMA Islam Athirah Bone merupakan sekolah yang menerapkan program ujian tanpa pengawasan untuk membentuk karakter siswa yang sesuai dengan nilai keislaman. Sesuai dengan apa yang diucapkan oleh kepala sekolah yaitu "budaya yang berkarakter islami, semua program sesuai dengan visi dan misi sekolah yaitu berkarakter Islami dan akhlak mulia yang mampu bersaing dengan ilmu pengetahuan dan teknologi", yang diterapkan dalam program ujian tanpa pengawasan. Kegiatan tersebut berjalan sesuai dengan jadwal yang telah ditentukan. Berdasarkan dari kegiatan tersebut yang terus menerus siswa dapat memiliki nilai karakter religius. Sedangkan menurut wakil kepala sekolah bidang kurikulum mengatakan 
bahwa karakter yang diterapkan disekolah dengan ujian tanpa pengawasan yaitu disiplin, mandiri, kepribadian, tanggung jawab dan religius. ${ }^{57}$ Hal tersebut menunjukkan adanya ujian tanpa pengawasan siswa bertujuan untuk pembentukan karakter siswa.

\section{Pembahasan Hasil Penelitian}

Suksesnya sekolah yaitu menjadikan keunggulan akademik namun tidak cukup hanya keunggulan akademik saja perlu adanya budaya sekolah menghantarkan siswa memiliki karakter yang positif, peduli lingkungan dan sosial, pedagogik dan kurikulum yang kuat, motivasi dan keterlibatan siswa yang tinggi. SMA Islam Athirah Bone memiliki visi dan misi yang mengedepankan nilai-nilai karakter yang dibiasakan dalam kegiatan sekolah baik dalam intrakuriler maupun ekstrakurikuler. Penerapan budaya ujian tanpa pengawasan dikembangkan melalui program-program khusus kesiswaaan yang membiasakan siswa berkarakter. Adapun dari 18 nilai karakter di sekolah ini hanya menekankan lima nilai karakter lebih ditekankan yaitu disiplin, bertanggung jawab, mandiri, jujur, kepribadian.

Selama ujian berlangsung pengawas ujian hanya duduk di luar di kelas. Pembiasaan ujian tanpa pengawasan bertujuan untuk pembentukan karakter siswa yang akan menjadi pembiasaan dalam kehidupan mereka yang bukan hanya dalam kondisi ujian. Siswa SMA Islam Athirah Bone memiliki sikap terbentuk dari pembiasaan yang dilaksanakan di sekolah sehingga budaya sekolah tersebut sangat efektif terhadap pendidikan karakter pada siswa. Ditambah dengan penguatan kandungan hadits yang relevan dengan pembentukan karakter tersebut. Budaya sekolah dengan program ujian tanpa pengawsan yang diterapkan melalui kurikulum dan kegiatan kesiswaan yang mempunyai peran signifikan dapat mendukung dalam membentuk nilai-nilai karakter siswa. Dan dalam pencapaiannya tentu pihak sekolah yang terkait saling bekerja dan mendukung agar budaya sekolah tersebut.

\section{KESIMPULAN}

Penerapan ujian tanpa pengawan di SMA Islam Athirah Boarding School dilaksanakan untuk melatih peserta didik agar memiki karakter yang islami sebagaimana target yang ingin dicapai yaitu melahirkan pemimpin yang Islami. Penerapan ujian tanpa pengawasan ini melalui beberapa tahapan yaitu : a) tahap sosialisasi yang dilakukan sejak pertama kali masuk dan dilakukan setiap saat dalam kegiatan sehari-hari, b. Tahap pelaksanan yang meliputi pemberian arahan oleh Kepala Sekolah, pembacaan dan penandatanganan fakta integritas, pembagian soal beserta lembar dan kunci jawaban kemudian penanggung jawab ruangan meninggalkan tempat. Kemudian penanggung jawab ruangan masuk kelas kembali 10 
menit sebelum ujian berakhir. c). Evaluasi kegiatan dimaksudkan untuk mengevaluasi hasil yang diperoleh dari ujian tanpa pengawasan.

Berdasarkan data yang diperoleh di lapangan dengan melihat indikator kejujuran, kepribadian, kemandirian, tanggung jawab dan kedisiplinan dan penjelasan dari beberapa responden maka dapat diambil kesimpulan bahwa penerapan ujian tanpa pengawasan terhadap pengembangan pendidikan karakter siswa berbasis hadis di SMA Islam Athirah Boarding School Bone berjalan sangat efektif. Dengan demikian teori yang dikemukan oleh Eagly dan Chaiken tentang teori perubahan sikap yaitu: a). Probabilogical model yaitu perubahan sikap ditentukan oleh keyakinan yang sudah dimilikinya yang bersifak subyektif. b) Expetancy value model yaitu perubahan sikap ditentukan oleh sekumpulan keyakinan tentang suatu obyek, perilaku dan peristiwa, teruji kebenarannya. Hal ini juga sejalan dengan teori Paul E Johnson yang mengatakan bahwa perilaku beragama seseorang dapat ditentukan oleh kesadaran syariat dan kesadaran spiritual mereka. Sehingga dengan demikian agama dapat berfungsi untuk menjaga kesusilaan atau tata krama dan tata tertib yang berlaku dalam masyarakat.

\section{REFERENSI}

Abdallah, Abdallah. "State, Religious Education, and Prevention of Violent Extremism in Southeast Asia." Studia Islamika 26, no. 2 (13 Agustus 2019): 407-15. https://doi.org/10.15408/sdi.v26i2.12204.

Abu 'Abd Allah Muhammad, Yazid al-Qazwiny Ibn Majah. Sunan Ibn Majah. Riyad: Maktabah al-Ma'arif, t.t.

Abu Abdullah, Muhammad bin Ismail. Shahih Bukhari. 4 ed. 1 vol. Beirut Lebanon: Dar alKotob Al-Ilmiyah, 2010.

Abu Husain Muslim, Al-Hajjaj. Shabih Muslim. 3 ed. 1 vol. Beirut Lebanon: Dar al-Kotob AlIlmiyah, 2010.

Abu 'Isa Muhammad, Isa al-Tirmidhy. Sunan al-Tirmidhy. Riyad: Maktabat al-Ma'arif, 2005.

Abudin, Nata. Ilmu Pendidikan Islam. 3 ed. Jakarta: Prenada Media Grup, 2016.

Amri, Muhammad, Saharuddin Saharuddin, dan La Ode Ismail Ahmad. "The Implementation of Islamic Education: The Process of Instilling Akhlakul Karimah (Noble Characters) for Madrasah Tsanawiyah Students." Tadris: Jurnal Keguruan Dan Ilmu Tarbiyah 4, no. 1 (28 Juni 2019): 117-25. https://doi.org/10.24042/tadris.v4i1.4070. 
Efektivitas Penerapan Ujian,..

Amrullah, Abdul Malik Karim. "Implementasi Pendidikan Karakter Di Madrasah.” Madrasab: Jurnal Pendidikan Dan Pembelajaran Dasar 4, no. 2 (23 November 2012). https://doi.org/10.18860/jt.v0i0.2183.

Ansori. "Internalisasi Nilai-Nilai Pendidikan Karakter Dilingkungan Madrasah Dan Sekolah." At-Tasyrib: Jurnal Pendidikan Islam 1, no. 1 (1 September 2015): 66-81.

Anwar, Chairul, Antomi Saregar, Uswatun Hasanah, dan Widayanti Widayanti. "The Effectiveness of Islamic Religious Education in the Universities: The Effects on the Students' Characters in the Era of Industry 4.0." Tadris: Jurnal Keguruan Dan Ilmu Tarbiyah 3, no. 1 (29 Juni 2018): 77-87. https://doi.org/10.24042/tadris.v3i1.2162.

Baharun, Hasan, dan Rohmatul Ummah. "Strengthening Students' Character in Akhlaq Subject Through Problem Based Learning Model." Tadris: Jurnal Keguruan Dan Ilmu Tarbiyah 3, no. 1 (29 Juni 2018): 21-30. https://doi.org/10.24042/tadris.v3i1.2205.

Baisuki, Asror, dan Ta'rif Ta'rif. "Penanaman Karakter Moderat Di Ma'had Aly Situbondo." EDUKASI: Jurnal Penelitian Pendidikan Agama Dan Keagamaan 15, no. 3 (31 Desember 2017). https://doi.org/10.32729/edukasi.v15i3.456.

Daradjat, Zakiah, dan Indonesia, ed. Ilmu pendidikan Islam. Cet. 2. Jakarta: Diterbitkan atas kerjasama Penerbit Bumi Aksara, Jakarta dengan Direktorat Jenderal Pembinaan Kelembagaan Agama Islam, Departemen Agama, 1992.

Dawam, A., A. Ta'arifin, dan K. Durori. Manajemen madrasah berbasis pesantren. Lista Fariska Putra, 2004. https://books.google.co.id/books?id=UjYdNAAACAAJ.

E Mulyasa. Manajemen Pendidikan Karakter. 5 ed. Jakarta: Bumi Aksara, 2016.

Eva Rukmana Thandra. Wawancara, Wakil Kepala Sekolah Bidang Kesiswaan SMA Islam Athirah Boarding School Bone, Agustus 2019.

Garcia, Danilo, Trevor Archer, dan Ann-Christine Andersson Arntén. Character, Responsibility, and Well-Being: Influences on Mental Health and Constructive Behavior Patterns, 2016.

Hadari Nawawi. Metode penelitian bidang sosial. Yogyakarta: Gadjah Mada University Press, 1993. Ichsan, Ichsan. "Pendidikan Nilai Kejujuran Berbasis Kelas Di Madrasah Ibtidaiyah Negeri 1 Bantul Yogyakarta." Edukasia: Jurnal Penelitian Pendidikan Islam 14, no. 1 (24 Juni 2019): 49-70. https://doi.org/10.21043/edukasia.v14i1.3664.

Imam, Suprayogo, dan Tobroni. Metodologi Penelitian Sosial Agama. Bandung: Remaja Rosdakarya, 2003.

Irwan, Prayitno. Pendidikan Karakter. 2012 ed. Singgalang, t.t. 
Kementerian Pendidikan Nasional. "Pengembangan Pendidikan Budaya dan Karakter Bangsa.” Badan Penelitian dan Pengembangan Pusat Kurikulum. Jakarta, 2011.

Kesuma, Dharma. Pendidikan karakter: kajian teori dan praktik di sekolah. Bandung: PT Remaja Rosdakarya, 2011.

Lickona, Thomas. Educating for Character: How Our Schools Can Teach Respect and Responsibility. New York: Bantam Books, 2009.

M. Jafar Anwar, dan M. A. Salam. Membumikan Pendidikan Karakter Implementasi Pendidikan Berbobot Nilai dan Moral,. Jakarta: Suri Tatư uw, 2015.

Ma`arif, Muhammad Anas. "Analisis Strategi Pendidikan Karakter Melalui Hukuman Preventif." Ta'allum: Jurnal Pendidikan Islam 6, no. 1 (6 Maret 2018): 31-56. https://doi.org/10.21274/taalum.2018.6.1.31-56.

Ma'arif, Muhammad Anas, dan Muhammad Husnur Rofiq. "The Model of Character Teacher: Phenomenology at Daruttaqwa Gresik Islamic Boarding School." ATTARBIYAH: Journal of Islamic Culture and Education 3, no. 2 (2 Januari 2019): 131-52. https://doi.org/10.18326/attarbiyah.v3i2.131-152.

Majid, Abdul, dan Dian Andayani. Pendidikan agama Islam berbasis kompetensi: konsep dan implementasi kurikulum 2004. Cet. 1. Bandung: Remaja Rosdakarya, 2004.

Muclas, Samani, dan Hariyanto. Konsep dan Model Pendidikan karakter. 6 ed. Bandung: Rosdakarya, 2017.

Ramayulis, dan Samsul Nizar. Filsafat pendidikan Islam: telaah sistem pendidikan dan pemikiran para tokohnya. Jakarta: Kalam Mulia, 2009.

Ramdani, Neila. "Teori Perubahan Sikap." dipresentasikan pada Makalah Pendidikan Program Doktor Fakultas Psikologi UGM, Yogjakarta, 2008.

Rapika Samsu. Wwancara, Wali Kelas XI IPA Al-Hasiib, SMA Islam Athirah Boarding School Bone, Agustus 2019.

Sapriadi. Wawancara, Guru Bahasa Inngris SMA Islam Athirah Boarding School Bone, September 2018.

Sufyarma, Marsidin. "Pendidikan Karakter di Pesantren." dipresentasikan pada Makalah Seminar RegionaTentang Pen- didikan Karakter STIT Ahlussunnah Bukittinggi, Bukittinggi, 2012.

Sulaiman bin al-Ash'ath, Al-Sijistany al-Azdy. Sunan Abu Dawud. Vol. 4. Beirut Lebanon: Dar Ibn Hazm, 1997.

Sulistyorini. Evaluasi Pendidikan dalam Meningkatkan Mutu Pendidikan. Yogjakarta: Teras, 2009. 
Efektivitas Penerapan Ujian,..

Suryana, Yaya. Pendidikan multikulkultural: suatu upaya penguatan jati diri bangsa: konsep-prinsipimplementasi. Cet. I. Bandung: Pustaka Setia, 2015.

Syamsul Bahri. Wawancara, Kepala Sekolah SMA Islam Athirah Boarding School Bone, Agustus 2019.

- Wawancara, Kepala Sekolah SMA Islam Athirah Boarding School Bone, September 2019.

Wibowo, Agus. Pendidikan karakter: strategi membangun karakter bangsa berperadaban. Cet. 1. Yogyakarta: Pustaka Pelajar, 2012.

Zubaedi. Desain Pendidikan karakter, Konsepsi dan Aplikasinya dalam Pendidikan. Jakarta: Kencana Prenada, 2011. 